Revue d'histoire de l'Amérique française

REVUE D.HISTOIRE DE L'AMÉRIQUE FRANÇAISE

\title{
Témoignages sur le chanoine Lionel Groulx
}

\section{Lucien Campeau}

Volume 21, numéro 2, septembre 1967

URI : https://id.erudit.org/iderudit/302686ar

DOI : https://doi.org/10.7202/302686ar

Aller au sommaire du numéro

Éditeur(s)

Institut d'histoire de l'Amérique française

ISSN

0035-2357 (imprimé)

1492-1383 (numérique)

Découvrir la revue

Citer ce document

Campeau, L. (1967). Témoignages sur le chanoine Lionel Groulx. Revue

d'histoire de l'Amérique française, 21(2), 354-358.

https://doi.org/10.7202/302686ar d'utilisation que vous pouvez consulter en ligne.

https://apropos.erudit.org/fr/usagers/politique-dutilisation/ 


\section{TÉMOIGNAGES SUR LE CHANOINE}

\section{LIONEL GROULX}

\section{SON SENS DE LA CULTURE}

Le regretté chanoine Lionel Groulx a été un type accompli du Canadien français cultivé. Qu'est-ce en effet que la culture, sinon l'expression à la fois pleinement consciente et parfaitement harmonieuse du fonds d'expériences et de réflexions qu'un peuple collige au long des siècles, dans l'alternance de ses réussites et de ses échecs, de ses joies et de ses douleurs. Il n'y a pas que les individus à être façonnés, assagis, intériorisés, anoblis par la vie et l'expérience. Les peuples le sont aussi. Et tous les souvenirs des événements vécus ensemble, tout l'héritage des ceuvres construites et des conquêtes accomplies forment un patrimoine, un trésor qui adhère à la chair, au sang, à la personnalité d'une race. On vit de ces traditions, le plus souvent sans le dire; on y est ordinairement fidèle, par instinct. Mais cela ne suffit pas à la vie d'un peuple, bien que ce soit nécessaire. Cela doit monter au niveau de l'intelligence collective, de l'action religieuse, sociale et politique, de l'expression artistique. Alors apparaît formée la culture d'un groupe ethnique: son témoignage particulier sur l'homme. Il y a des contrefaçons d'humanisme: celui d'un esprit en rupture avec les aspirations inexprimées mais vécues par le peuple. L'humanisme n'est pas qu'intelligence; il est intelligence en consonance affective avec un milieu social et historique. Et lorsqu'il apparaît, apparaissent aussi une pensée et une action propres à hausser le peuple au-dessus de lui-même, dans la fidélité à ce que l'expérience historique a fait de lui.

Cet humanisme, le chanoine Groulx l'a créé en lui-même. Enfant de nombreuses générations paysannes, il a puisé son âme dans le terroir natal. Il a aimé la terre des ancêtres, le parler de ses pères, la sagesse des anciens, la foi de sa communauté ecclésiale. Et sa mort, au lieu où il était né, est le signe de sa fidélité. Sa haute intelligence, ses études, les tâches auxquelles il fut appelé l'élevèrent au-dessus de la foule. Il a toujours été à la mesure de ses responsabilités, mais il n'a jamais cessé d'être le fils de la terre de Vaudreuil. De la sève de cette terre il a formé les fruits que sont ses ouvres. Bien enraciné en un lieu aussi précis, il a été vraiment fils de notre peuple, auquel sa langue a été familière et sa pensée intelligible; à bon droit il a été tenu par ce peuple prophète qui le révélait à lui-même, un guide qui ne l'a jamais ni trompé ni trahi. L'histoire de notre patrie, discipline à laquelle le chanoine a donné un tour désormais irréformable, servait à souhait les hautes passions de son intelligence. Il a fait d'elle un stimulant et un flambeau du vouloir-vivre national, éclairant par elle l'avenir de notre pays. Tout ce que le chanoine était, il l'a tiré de son peuple de la Nouvelle-France, déjà héritier de grandes cultures, et il a versé en retour au patrimoine commun la pénétration de son intelligence, la chaleur de son cour et l'enchantement de son verbe. Et c'est pourquoi, si entièrement nôtre, il a été si véritablement homme.

LUCIEN CAMPEAU 
Nous avons pensé qu'il intéresserait nos lecteurs de pouvoir lire quelques extraits des nombreux témoignages reçus ou publiés lors du décès du fondateur de la Revue.

Pour tout ce peuple qu'il a aimé, la vie ne sera plus la même... Il est tombé en plein travail, il est tombé comme un grand arbre, chargé d'œuvres.

Pour ma part, l'abbé Groulx m'a formé. Il a été le premier de mes maîtres. Il a inspiré par son exemple les recherches que j'ai faites...

Sans l'abbé Groulx, la génération de ce qu'il a appelé les jeunes historiens - mais qui ont tout de même 50 ans aujourd'hui - ne serait pas ce qu'elle est.

\section{Guy Frégault}

sous-ministre des Affaires culturelles

Le chanoine Groulx est l'un des quelques géants que nous pouvons compter. Il fut, comme Marie-Victorin et Edouard Montpetit de ceux qui ont vraiment tracé quelque chose au Canada français. Comme tous ceux qui ont apporté une contribution valable, Lionel Groulx possédait l'inquiétude nationaliste: il savait que si la science n'a pas de pays, les hommes de science, eux, ont une patrie ... Le chanoine Groulx possédait un jugement très sûr sur les hommes, ce qui est une qualité essentielle chez un historien.

\section{Michel BRUNET}

Le Devoir, 24 mai 1967

Lionel Groulx a été un maître, il demeure un exemple et un symbole. Comme maître il a eu une influence directe et profonde sur plus de deux générations de penseurs du milieu canadienfrançais. Son œuvre imposante caractérisée par une grande discipline intellectuelle et une recherche systématique a profondément influencé la discipline de l'histoire à l'intérieur de nos frontières.

\section{Michel NORMANDIN \\ président de l'ACFAS}

J'ai toujours eu beaucoup d'amitié et ressenti beaucoup d'admiration à son égard. Je garderai toujours le souvenir de son charme, de son patriotisme intense et de son intégrité comme historien. Notre amitié commença le jour où je lui envoyai ma 
première lettre alors que j'étais à l'université de la Colombie Britannique, et elle m'a été, durant ces vingt dernières années, une source constante d'agréments et d'enrichissements.

\section{G.F.G. STANLEY \\ Doyen de la Faculté des Arts \\ Collège militaire royal \\ Kingston, Ont.}

J'ai été très affecté par la mort de M. le Chanoine Groulx, ce véritable maître de l'historiographie canadienne. Je ne sais s'il sera continué. A la rigueur de la méthode, il savait unir cette flamme qui fait découvrir dans l'histoire autre chose qu'une succession brutale de faits, et dans leur exposé autre chose qu'une pure technique. Il écrivait enfin en chrétien et en prêtre, en même temps qu'en fils du terroir; cela n'enlève rien aux qualités du savant.

Chanoine Etienne CATTA professeur à la Faculté des Lettres de l'Université catholique de Lille

Je ne sais laquelle de ses vertus, car il en avait plusieurs, perpétuera le nom du chanoine Groulx, mais s'il m'était permis de choisir parmi toutes celles qui me l'ont rendu si cher, j'opterais pour la discipline et tant est qu'à notre époque d'invertébrés ce mot ait encore un sens.

Victor BARBEAU

président de l'Académie

canadienne-française

Chez Fides, le 23 mai 1967

25 juillet 1967

Un assez long séjour hors de France m'a laissé ignorer la mort du très cher et très admiré $M$. le chanoine Groulx. J'avais eu l'honneur de l'approcher à Paris lors d'un de ses voyages, pendant l'hiver 1920-21 ou au printemps 1921 et je l'avais revu lors de mon séjour au Canada, après cette dernière guerre. Sa mort laisse un grand vide et me cause une peine bien sincère, dont je vous prie de faire part à ses amis et collaborateurs, en agréant, monsieur, l'expression de mon attachement très fidèle.

Pierre GaxoTtE de l'Académie française

Nous sommes accoutumés depuis si longtemps à le voir ne pas mourir, à le voir toujours digne, toujours fier et fort, au 
poste d'avant-garde, que nous ne pouvons pas nous faire à l'idée de nous passer de sa présence, de sa personnalité puissante, de sa pensée et de sa parole.

\author{
Mgr Victor TREMBLAY \\ président-fondateur de la \\ Société historique du Saguenay
}

La Revue d'Histoire de l'Amérique française symbolise l'ultime effort de M. Groulx en vue de ce qui a été le but de toute sa vie: le relèvement du peuple canadien-français, son acheminement définitif vers l'émancipation totale et l'épanouissement culturel, sous l'égide d'une solide foi religieuse.

\title{
Antoine BERNARD \\ Le Travailleur, Worcester \\ 8 juin 1967
}

Il convient donc d'ajouter à ce monument de reconnaissance le modeste tribut des Franco-Américains, car si la présente génération des jeunes ne connaît pas l'influence du chanoine Groulx, nous aimons à rappeler qu'il visita souvent nos centres pour nous apporter chaque fois des messages de persévérance.

Nul ne fut plus de son temps car ce grand explorateur de notre histoire regardait toujours vers l'avenir tout en chérissant le passé des ancêtres...

\section{Mgr Adrien VERRETTE \\ Le Canada-Américain avril-mai-juin 1967}

Nous perdons dans la personne du Chanoine Groulx celui qui a toujours fait honneur aux siens partout où on l'entendait, ou on le lisait, où on l'étudiait. Quelle ne fut pas ma surprise un jour de rencontrer chez monsieur Gabriel Ollivier, directeur du tourisme de Monaco, un lecteur assidu et un admirateur des œuvres de Groulx.

Me F.-Eugène THERRIEN

lettre du 30 mai à Mme Rémillard

Il y eut peu de grands événements, les tragiques comme les réconfortants, depuis un demi-siècle, peu d'innovations chez nous, à n'avoir pas porté la marque de Groulx, lorsqu'ils n'étaient pas une conséquence directe de son action. ... La plupart des nations ont eu à un moment ou l'autre de leur histoire et plusieurs à de nombreuses reprises, un "combattant suprême". Personne, chez nous, n'aura joué dans le dernier demi-siècle, un rôle équivalent 
au même point que ce prêtre d'aspect fragile, mais d'une foi et d'une volonté également indomptables.

\section{Jean-Marc LÉGER \\ Le Devoir, 24 mai 1967}

Pour les nationalistes canadiens-français, surtout pour ceux du Québec, la perte de l'abbé Groulx est énorme. Elle est, en toute justice, très grande aussi pour tout le Québec, même pour le Canada tout entier. L'abbé Groulx était et demeurera un historien de grande classe. On discute, et discutera longtemps l'interprétation qu'il a donnée aux événements historiques, mais on ne pourra jamais mettre en doute sa grande sincérité.

Alvarez VAILLANCOURT

La Tribune, Sherbrooke, 25 mai 1967

On lui reprochera peut-être un certain sentimentalisme dont les scientifiques aiment aujourd'hui à vider l'histoire, mais nul historien n'aura montré autant que lui son amour pour son peuple. Jamais il ne parvenait à agir en clinicien désincarné; il préférait éprouver dans sa chair les tourments de sa nation. Il en vibrait, il en souffrait. Qui voudrait lui en faire reproche?

\section{Laurent LAPLANTE \\ Québec, L'Action, 24 mai 1967.}

... Il est une phrase qui semble résumer tout un pan de l'homme. Il était nationaliste, commença-t-il par dire, parce qu'il était prêtre. La réalité de la foi n'était pas abstraite, irréelle. Elle était pétrie dans les circonstances concrètes de la collectivité.

\section{Michel de SALABERRY \\ Le Droit, 3 juin 1967}

Il avait à l'extrême ce mélange de simplicité et de courtoisie qui devrait être toujours la marque des esprits vraiment supérieurs. Mais parfois, devant une objection, on sentait brusquement passer de l'acier dans un simple changement d'intonation. Sous l'enveloppe d'oiseau, on percevait une ténacité - et une capacité de violence - dignes d'un taureau de combat.

Ceux qui l'ont vraiment connu ont certes eu de la chance. De même que le peuple qui l'a produit et a pu si longtemps compter sur lui.

René LÉVESQUE

Dimanche-Matin, 28 mai 1967 